\title{
Adherence of Mouse Peritoneal Macrophages Following Exposure to Lead
}

\author{
Rosa VillanUeVA*, Romana AlbaladeJo, Paloma ORTEga, Paloma AStaSio, \\ $M^{a}$ Elisa CALLE, Angel GIL, Belén GRANADOS and Vicente DOMÍNGUEZ-ROJAS
}

Facultad de Medicina, Universidad Complutense de Madrid, Pabellón 2-2a planta, Madrid, 28040, España

Received August 7, 1996 and accepted January 22, 1997

\begin{abstract}
Lead is a toxin widely used in industry. Recently, medical investigation into lead exposure has turned to testing organ systems, such as the immune system, that historically were not associated with lead poisoning. We evaluated the effects of doses of $13,130 \mathrm{or} 1,300 \mathrm{ppm}$ of lead on the adherence of mouse peritoneal cells, and particularly on macrophages. Cellular adherence was measured according to the De la Fuente technique. Adherence of macrophages showed significant changes in the $1,300 \mathrm{ppm}$ group, revealing a reduction to $55 \%$ of the control group. The macrophage adherence index showed $91 \%$ sensitivity and $96 \%$ specificity. These results indicate a considerable reduction in the adherence of peritoneal macrophages following exposure to certain levels of lead.
\end{abstract}

Key words: Lead, Peritoneal cell, Macrophages, Adherence

At present we know that previously considered acceptable levels of lead are not entirely harmless ${ }^{1)}$. Occupational standards for lead levels are being gradually lowered in many countries. Moreover the scientific spectrum of hazardous effects from lead exposure has been extended to the immune system.

Different doses of lead provoke changes in the immune systems of both animals ${ }^{2)}$ and workers ${ }^{3-5)}$. Antigen presentation is reduced, and the chemotaxis and phagocytosis of leukocytes are lowered ${ }^{4,6,7)}$. Add to this, a decrease in humoral and cellular immunity actions which require macrophage co-operation ${ }^{2)}$.

Because many of the aforementioned functional changes, following exposure to lead, could be due to a change in macrophage adherence, our study was designed to examine adherence activity of peritoneal macrophages in lead-exposed mice.

Forty female mice (BALB/c), supplied by Charles River were divided into four groups of ten each. Animals were housed in a temperature controlled room $\left(22^{\circ} \mathrm{C}\right)$ with a $12 \mathrm{hr}$ light/dark cycle. Mice were 4 weeks \pm 4 days (mean \pm S.D.)

*To whom correspondence should be addressed. old at the start of the tests. They were exposed to lead for a period of 10 weeks, with the $\mathrm{Pb}$ concentration levels varying in their drinking water from $0,13,130$ or 1,300 ppm (lead acetate, Panreac, Spain). Water was administered ad libitum.

The animals were assigned at random to four groups and their weight gain ( $\mathrm{g}$ ) and liquid consumption ( $\mathrm{ml} /$ day) were recorded weekly throughout the experiment. Renal lead concentration was also monitored to ascertain individual lead exposure levels.

At the end of this ten-week period, mice were cervically dislocated and their renal lead content was measured with an atomic absorption spectrophotometer.

Peritoneal cells were harvested by ip injection of $4 \mathrm{ml}$ RPMI-1640 (Sigma, USA) with $10 \mathrm{mM}$ of N-2hydroxyethylpiperazine-N'-2-ethanosulfonic acid (HEPES, Sigma, USA). We formed 3 aliquots and counted the number of cells in each aliquot with a hemocytometer. We calculated the averaged number of cells from the three aliquots. Two cytosmears of peritoneal cells were taken from each animal using the modified procedure of Brummer et al. ${ }^{8)}$ and we stained them using Diff-Quick ${ }^{\circledR}$ (Baxter Dade, Switzerland). To determine the composition of the slides, we classified 200 cells at random. The percentage of macrophages was 
multiplied by the average number of peritoneal cells, to calculate the total number of macrophages.

Cellular viability was checked, using blue trypan dye (Merck, Germany) at $0.4 \% /^{9}$. Macrophage viability was always higher than $97 \%$.

Adherence was assayed using the De La Fuente method ${ }^{10}$. The culture adherence medium consisted of RPMI-1640 and $10 \%$ calf foetal serum (FCS, Gibco, USA). Three sterilized MIF plastic culture dishes were used (Sterilin, Spain) per mouse, to which we added $200 \mu \mathrm{l}$ cellular suspension at a concentration of 500,000 macrophages per $\mathrm{ml}$. The dishes were left for two $\mathrm{hr}$ in a humid atmosphere at $37^{\circ} \mathrm{C}$, after which we harvested the non-adhered cells by 3 lavages with Hank's medium $\left(0^{\circ} \mathrm{C}\right)$. These cells were then counted with a hemacytometer. Each dish was counted twice.

The adherence index was calculated as follows:

(initial no. of macrophages/dish - no. of supernatant macrophages) initial no. of macrophages/dish $* 100$

Results from the 4 exposure groups were compared by analysis of variance (ANOVA). Where this method was not possible (i.e. under other than normal conditions, without homogeneous variance), the non parametric Kruskall-Wallis test $^{11)}$ was used. In cases of significant results at $p<0.05$, the groups which led to a rejection of the null hypothesis (Ho) by means of 'a posteriori orthogonal contrasts' were identified, using the Scheffé test ${ }^{11)}$.

It was decided that, if adherence were statistically modified, its diagnostic value would be evaluated by its sensitivity and specificity, in accordance with the method of Hulley and Cummings ${ }^{11}$. Sensitivity and specificity were determined by comparing the presence or absence of cellular adherence inhibition with the presence or absence of lead intoxication. Renal lead intoxication was used as a golden standard, with the cut-off point being set at $25 \mu \mathrm{g}$ lead/g dry kidney weight. This level is the previously established lead intoxication threshold for mammals ${ }^{12}$. In the case of the adherence index, the cut-off point was the average minus $2 \mathrm{SD}$ of control group.

$\begin{array}{cc}\begin{array}{c}\text { Sensitivity was } \\ \text { calculated as: }\end{array} & \begin{array}{c}\text { No. of intoxicated mice with } \\ \text { adherence inhibition }\end{array} \\ { } * 100 } \\ \begin{array}{c}\text { Specificity was } \\ \text { determined by: }\end{array} & \begin{array}{c}\text { No. of non-intoxicated mice } \\ \text { without inhibition of adherence }\end{array}\end{array}$

Weight gain in the mice was not significantly different among the four groups throughout the exposure period (data not shown). The average daily liquid consumption was 3.69 $\pm 0.37,3.72 \pm 0.61,3.56 \pm 0.23$ and $3.66 \pm 0.22 \mathrm{ml} /$ day for the control group and groups exposed to 13,130 and 1,300 ppm, respectively. No statistical differences were found under the Kruskall-Wallis test. These results, for growth rate and liquid consumption in the four groups, confirm the animals' welfare, also evidenced by their failure to refuse the liquid on the basis of its organoleptic nature.

We took the renal $\mathrm{Pb}$ concentration as a reference indicator for $\mathrm{Pb}$ exposure. Only the mice exposed to $1,300 \mathrm{ppm}$ exceeded the diagnostic threshold of lead intoxication in mammals $(25 \mu \mathrm{g} \text { lead/g dry kidney weight })^{12}$. With respect to the adherence index of macrophages no statistical differences were found in the groups exposed to 13 and 130 ppm and there was a considerable reduction, to $55 \%$ of the control group, in the group exposed to 1,300 ppm (Table). Scheffé's test revealed statistical differences in the group exposed to 1,300 ppm when compared with the control group and those groups exposed to 13 and $130 \mathrm{ppm}$. The macrophage adherence index showed $91 \%$ sensitivity and $96 \%$ specificity.

The immune system is composed of a cellular group, in which basic functions such as chemotaxis, phagocytosis as well as the adherence of monocytes in endothelial cells, depend on the adherence process ${ }^{13)}$. In previous studies, a change in the chemotaxis and phagocytosis has been revealed, following exposure to lead, in workers and animals ${ }^{4,6,7)}$. For this reason, we decided to concentrate on cellular adherence. In the group exposed to $1,300 \mathrm{ppm}$, considerable inhibition in the cellular adherence index was evident. This finding was corroborated by a reduction in the cytoplasmatic

Table. Adherence index of peritoneal macrophages

\begin{tabular}{cc}
\hline Lead acetate dose $^{\mathrm{a}}$ & Adherence index \\
\hline $0 \mathrm{ppm}$ & $85.60 \pm 17.12$ \\
$130 \mathrm{ppm}$ & $84.77 \pm 23.27$ \\
$1,300 \mathrm{ppm}$ & $47.74 \pm 16.50^{\mathrm{b}}$ \\
\hline
\end{tabular}

${ }^{a}$ Lead acetate was given by drinking water $\mathrm{ad}$ libitum from age 4 trough 14 weeks. Peritoneal macrophages were adhered during $2 \mathrm{hr}$, after we harvested non adhered cells by 3 lavages and the percentage of macrophages adhered was calculated. 'Significant difference from 0 ppm at $\mathrm{p}<0.0001$ (ANOVA). 
extension of monocyte-macrophages ${ }^{7)}$, and is a likely consequence of $\mathrm{Pb}$ acting on adherence molecules or integrins.

Monocyte-macrophages, and other leukocytes, contain numerous integrins, such as the leukocyte function associated with the antigen 1 (LFA-1), the macrophage antigen 1 (MAC1) or complement receptor 3 (CR3) and the complement receptor 4 (CR4). A common factor to all integrins is their high content of cysteine, especially in the subunit $\beta$ and the transmembrane area, where they constitute $7.4 \%$ and $20 \%$ respectively. In view of its great affinity to the sulfhydryl groups, lead could alter the adherence molecules and their function. The location of the majority of the sulfhydryl groups in the transmembrane are ${ }^{13)}$ would explain the $\mathrm{Pb}$ 's difficult access to this zone, and why only maximum doses of lead cause inhibition there.

Lead could also reduce adherence by altering the composition and fluidity of the macrophage membrane ${ }^{14,15)}$. Such changes would in turn affect integrin adherence capacity.

Alteration of the adherence index revealed high sensitivity. We noted considerably reduced adherence in the majority of the animals which had passed the $25 \mu \mathrm{g}$ lead/g dry kidney weight ${ }^{12)}$ whereas, the adherence index were unaltered in the majority of the mice which had not exceeded the lead intoxication threshold, which is consistent with the high specificity in these animals.

It can be concluded from the present study that the reduction of adherence is related to an increase in the level of lead exposure. In view of these results we think it is necessary to further examine the procedures by which lead affects adherence levels.

\section{Acknowledgments}

We would like to thank Ms Hilary Keller for preparing the manuscript in English.

\section{References}

1) Lippmann M(1990) Lead and human health: background and recent findings. Environ Res 51, 1-24.

2) Koller LD (1990) The immunotoxic effects of lead in lead exposed laboratory animals. Ann NY Acad Sci 587, 160-7.

3) Coscia GC, Discalzi G, Ponzetti C(1987) Immunological aspects of occupational lead exposure. Med Lav 78,
$360-4$.

4) Governa M, Valentino M, Visona I, Scielso R (1988) Impairment of chemotaxis of polymorphonuclear leukocytes from lead acid battery workers. Sci Total Environ 71, 543-6.

5) Fischbein A, Tsang P, JCh Luo, Bekesi JG (1993) The immune system as target for subclinical lead related toxicity. Br J Ind Med 50, 185-6.

6) Mauël J, Ransijn A, Buchmüller-Rouiller Y (1989) Lead inhibits intracellular killing of Leishmania parasites and extracellular cytolisis of target cells by macrophage exposed to macrophage activating factor. J Leukocyt Biol 45, 401-9.

7) Kowolenko M, Tracy L, Lawrence DA (1989)' Lead induced alterations of in vitro bone marrow cell responses to colony stimulating factor-1. J Leukocyt Biol 45, 198-206.

8) Brummer E, McEwen JG, Stevens DA (1986) Fungicidal activity of murine inflammatory polymorphonuclear neutrophils: comparison with murine peripheral blood PMN. Clin Exp Immunol 66, 681-90.

9) Herscowitz HB, Cole DE (1981) Maintenance of macrophages in vitro. In: Manual of macrophage methodology. Collection, characterization, and function. eds. by Herscowitz HB, Holden HT, Bellanti JA, Ghaffar A, 161-9, Marcel Dekker, New York.

10) De la Fuente $M$ (1985) Changes in the macrophage function with aging. Comp Biochem Physiol 81A, 9358.

11) Hulley SB, Cummings SR (1993) Diseño de la investigación clínica. Un enfoque epidemiológico, Ediciones Doyma SA, Barcelona.

12) Ma WC (1989) Effect of soil pollution with metallic lead pellets. Arch Environ Contam Toxicol 18, 617 22.

13) Kishimoto TK, Larson RS, Corbi AL, Dustin ML, Staunton DE, Springer TA (1989) The leukocytes integrins. Adv Immunol 46, 149-75.

14) Johnson JV, Montoya IA, Olive DL (1992) Ethiodol oil contrast medium inhibits macrophage phagocytosis and adherence by altering membrane electronegativity and microviscosity. Fertil Steril 58, 511-7.

15) Valentino M, Fiorini RM, Curatola G, Governa M (1982) Changes of membrane fluidity in erithrocytes of lead exposed workers. Int Arch Occup Environ Health 51, 1052. 